\title{
SELECTING TARGET MARKET BY SIMILAR MEASURES IN INTERVAL INTUITIONISTIC FUZZY SET
}

\author{
Nguyen Xuan THAO${ }^{1}$, Truong Thi Thuy DUONG ${ }^{2^{*}}$ \\ ${ }^{1}$ Faculty of Information Technology, Vietnam National University of Agriculture, \\ Gia Lam-Ha Noi, Viet Nam \\ ${ }^{2}$ Banking Academy, 12 Chua Boc, Ha Noi, Viet Nam
}

Received 18 September 2018; accepted 16 March 2019

\begin{abstract}
The selection of the target market plays vital role in promoting the marketing strategies of companies. We presented is a method for target market selection. We introduce some novel similarity measures between intuitionistic fuzzy sets and the novel similarity measures between interval-valued intuitionistic fuzzy sets. They are constructed by combining exponential and other functions. Finally, we introduce a multi-criteria decision making model to select target market by using the novel similarity measure of interval intuitionistic fuzzy sets.
\end{abstract}

Keywords: intuitionistic fuzzy set, interval - valued intuitionistic fuzzy set, similarity measure, target market, market segment.

JEL Classification: C02, C44, D40, D81.

\section{Introduction}

The target market consists of a set of customer groups having common needs or characteristics that the organizations wish to serve. The selecting of target market helps the suppliers choosing which and how many segments to serve (Bernstein, 2014). Businesses understand that customers are diverse in demands, attitudes and preferences. There is no organization which can satisfy all customers in the markets. Instead of competing in the marketplace, trying to fight against competitors, they should identify the most attractive segment that they can provide effectively (Bernstein, 2014; Kotler \&Armstrong, 2003). Marketing strategies allow organizations to find out and develop markets or tailor their services to meet the needs of potential markets. There are normally three ways to reach the market: mass marketing, target marketing and consumer marketing. Mass marketing, which assumes that all customers are treated similarly, will no longer be effective in the coming century (Kuo, Ho \& Hu, 2002). Instead, it will be a targeted marketing strategy, which identifies target segments and

${ }^{\star}$ Corresponding author. E-mail: thuyduongktv@yahoo.com.vn

This is an Open Access article distributed under the terms of the Creative Commons Attribution License (http://creativecommons. org/licenses/by/4.0/), which permits unrestricted use, distribution, and reproduction in any medium, provided the original author and source are credited. 
marketing plans that fit into it (Kotler \& Armstrong, 2003). Market segmentation also raises profit or effectiveness of firms (Chiu, Chen, \& Kuo, 2009). Besides that, it helps businesses to recognize the position of their product on the market, explore new opportunities and gain competitive advantages through differentiation of the product (Kotler, 1980). Any segmentation scheme should have the following characteristics: exhaustiveness, reliability and operability. By analyzing the attractiveness of each segment, managers make strategic decisions about their sources and finance for each segment, deciding on quality of the product, price and finally determining the time introduce goods to the market (Bernstein, 2014).

There are a lot of methods to segment the market but not all segments are effective. Kotler and Armstrong (2003) pointed out an example of the salt market to prove this claim. It is clear that race or ethical dispositiondoes not affect the amount of salt consumption, so this segment is not effective. According to the authors, the market segment should have the following criteria: measurable, accessible, substantial and actionable. In Simkin and Dibb's view (1998), target marketing plays a key role in making a decision for firms. Although the activities of marketers are changing on the market, selecting the target market is still an important strategic issue. It is necessary to study the market attractiveness criteria. Market size, exchange rate growth, competitive forces, appropriate customers and profits are just a few of the many criteria that can be applied to assess the attractiveness of a target market of an enterprise. The study also found that many firms continue to evaluate target markets on the basis of short-term profit-taking measures. The target market is the center of the marketing decisions, which are seen as the output of evaluation and selection the market segmentation (Aghdaie, 2015). Selecting the target segment is a complex process that takes into account many factors such as the segment's expected response to marketing variables, the likelihood of success, the competitive nature of the segment management resources and the ability to deploy segmentation strategies (Winter, 1979). Thus, the target market selection can be considered as a multi-criteria decision making model.

A well-known and useful method for selecting the most suitable alternative from a set of alternatives is the multi-criteria decision making (MCDM). It has been applied widely to the complexity of economic decision problems as well as many other fields. In these cases, it is difficult for the makers to show their opinions by crisp numbers, so the linguistic variables is used efficiently. The linguistic variables have been recognized as a useful approach in decision making problems. In 1986, Atanassov generalized Zadeh's fuzzy set (Xu, 2010) by introducing the intuitionistic fuzzy set (IFS) (Atanassov, 1986), which considers the information for both the membership function and non-membership function. From its inception to the present day, IFS proved to be very effective in dealing with the uncertainty in the real-world problems such as the pattern recognition, the decision making, etc. After that, the intervalvalued intuitionistic fuzzy set (IVIFS) was introduced by Atanassov and Gargov (1989), in which the membership function and non-membership function are subintervals of $[0,1]$. As opposed to fuzzy sets, intuitionistic fuzzy (IF) set also has broad applications for uncertain data processing such as decision making, medical diagnosis, agriculture, image segmentation (Buhaesku, 1988; Hung \& Wu, 2002; Mitchell, 2004; Szmidt \&Kacprzyk, 2004; Ye, 2011; Park, Hwang, Park, Wei \& Lee, 2013; Shi \& Ye, 2013; Shidpour, Bernard \& Shahrokhi, 2013; Bharati \& Singh, 2014; Li \& Zeng, 2015; Liu, Shen, Mu, Chen \& Chen, 2016; Zhou, Zhao, Yu \& Tian, 2016). Along with distance measurements, correlation measurements, similar 
measurement of IF sets and interval IF sets is also studied and widely used in many areas and now it still is a hot topic (Chiang \& Lin, 1999; Gerstenkorn \& Mańko, 1991; Ye, 2016). Similarity measures are tools to show the similarity of two objects. It is useful to handle the problems such as decision making, machine learning, pattern recognition (Szmidt \& Kacprzyk, 1996; Liang \& Shi, 2003; Hwang, Yang, Hung \& Lee, 2012; Li \& Cheng, 2002; Xu, 2007b; Zeng \& Wang, 2011; Ye, 2011; Park, Hwang, Park, Wei \& Lee, 2013). The similarity measure (SM) between IF sets were introduced by Liang and Shi (2003) and applied in the pattern recognition problem. Xu (2006) developed the similarity measure which constructed by the distance measure in multi-criteria decision making. This problem was proposed and applied in the multi-criteria decision making by Zhou (2016). The proposed methods used polynomial functions or fractional functions. Ye (2016) generalized new version of weighted cosine similarity measures between two IF sets through the degrees of membership, nonmembership and hesitancy in IF sets and applied to mechanical decision schemes using intuitionistic fuzzy numbers. Phong and Son (2017) resolved linguistic classification problem by the linguistic SM, the linguistic vector, and the linguistic vector similarity.

The existing models which evaluate and select market segment or target market, usually use the triangular or trapezoidal fuzzy numbers to express the assessment of decision makers (DMs) (see for example Aghdaie, Zolfani \& Zavadskas, 2013). The interval-valued intuitionistic fuzzy set is a stronger tool in reflecting the vague features of the subjective judgments of the DMs. The proposed similarity measures of Shi and Ye (2013), Ye (2016) have been successfully applied in classification or pattern recognition, however, they were not effective in some cases. These inspire us to introduce a new similarity measure of intuitionistic fuzzy sets which can overcome some drawbacks and apply the new measure for selecting target market. The rest of this paper is as follows. In Section 1, we recall the concept of intuitionistic fuzzy set, interval-valued intuitionistic fuzzy set and the similarity measure of them. The new similarity measure between the IFSs were built by combining exponential and other functions in Section 2 and we will compare the results computed by our method to other ones. The similarity measure of the interval-valued intuitionistic fuzzy sets is proposed in Section 3. In Section 4, we use the similarity measure of interval-valued intuitionistic fuzzy sets in multi-criteria decision making model. Section 5, a case study will cary out to apply the new measure for target market selection. Finally, we compare the proposed method with some existing models.

\section{Preliminary}

Let $X$ be a universal set. We recall the concepts of IFS and interval-valued intuitionistic fuzzy set (IVIFSs) on $X$.

Definition 1. (Atanassov, 1986) An IFS $X$ is defined by form

$$
A=\left\{\left(x, \mu_{A}(x), v_{A}(x)\right) \mid x \in X\right\},
$$

in which $\mu_{A}(x) \in[0,1]$ is the membership degree and $v_{A}(x) \in[0,1]$ is the non-membership of the element $x$ in $X$ to $A$, respectively such as

$$
\mu_{A}(x)+v_{A}(x) \leq 1, \forall x \in X .
$$


For two IF sets $A, B \in \operatorname{IFS}(X)$ we have:

$-A \subset B$ if only if $\mu_{A}(x) \leq \mu_{B}(x)$ and $v_{A}(x) \geq v_{B}(x)$ for all $x \in X$.

- $A=B$ if only if $\mu_{A}(x)=\mu_{B}(x)$ and $v_{A}(x)=v_{B}(x)$ for all $x \in X$.

- The complement of intuitionistic fuzzy set $A$ is

$$
A^{C}=\left\{\left(x, v_{A}(x), \mu_{A}(x)\right) \mid x \in X\right\} .
$$

Definition 2. (Atanassov, 1989) An interval - value IFS on $X$ is a defined by form

$$
A=\left\{\left(x,\left[\mu_{A}^{L}(x), \mu_{A}^{U}(x)\right],\left[v_{A}^{L}(x), v_{A}^{U}(x)\right]\right) \mid x \in X\right\},
$$

in which $\left[\mu_{A}^{L}(x), \mu_{A}^{U}(x)\right] \subseteq[0,1]$ and $\left[v_{A}^{L}(x), v_{A}^{U}(x)\right] \subseteq[0,1]$ are the membership degree and the non-membership of the element $x$ in $X$ to $A$, respectively, and

$$
\mu_{A}^{U}(x)+v_{A}^{U}(x) \leq 1, \forall x \in X .
$$

Let $A, B \in \operatorname{IVIFS}(X)$, we have some following characteristics (Xu, 2007a):

- $A \subset B$ if only if $\mu_{A}^{L}(x) \leq \mu_{B}^{L}(x), \mu_{A}^{U}(x) \leq \mu_{B}^{U}(x)$ and $v_{A}^{L}(x) \geq v_{B}^{L}(x), v_{A}^{U}(x) \geq v_{B}^{U}(x)$ for all $x \in X$.

- $A=B$ if only if $\mu_{A}^{L}(x)=\mu_{B}^{L}(x), \mu_{A}^{U}(x)=\mu_{B}^{U}(x)$ and $v_{A}^{L}(x)=v_{B}^{L}(x), v_{A}^{U}(x)=v_{B}^{U}(x)$ for all $x \in X$.

- Complement of the interval - value IFS $A$ is

$$
A^{c}=\left\{\left(x,\left[v_{A}^{L}(x), v_{A}^{U}(x)\right],\left[\mu_{A}^{L}(x), \mu_{A}^{U}(x)\right]\right) \mid x \in X\right\} .
$$

For convenience, we denote $x=\left(\left[\mu^{L}, \mu^{U}\right],\left[v^{L}, v^{U}\right]\right)$ with $\left[\mu^{L}, \mu^{U}\right] \subseteq[0,1],\left[v^{L}, v^{U}\right] \subseteq$ $[0,1]$ and $v^{U}+\mu^{U} \leq 1$ to show the value in IVIFs, and call it the interval intuitionistic fuzzy value.

Definition 3. (Xu, 2007a). Let $\mathrm{x}$ and $\mathrm{y}$ be two interval intuitionistic fuzzy values. We have the following basic operations:

$$
\begin{aligned}
& x \oplus y=\left(\left[\mu_{1}^{L}+\mu_{2}^{L}-\mu_{1}^{L} \mu_{2}^{L}, \mu_{1}^{U}+\mu_{2}^{U}-\mu_{1}^{U} \mu_{2}^{U}\right],\left[v_{1}^{L} v_{2}^{L}, v_{1}^{U} v_{2}^{U}\right]\right) ; \\
& x \otimes y=\left(\left[\mu_{1}^{L} \mu_{2}^{L}, \mu_{1}^{U} \mu_{2}^{U}\right],\left[v_{1}^{L}+v_{2}^{L}-v_{1}^{L} v_{2}^{L}, v_{1}^{U}+v_{2}^{U}-v_{1}^{U} v_{2}^{U}\right]\right) ; \\
& n x=\left(\left[1-\left(1-\mu_{1}^{L}\right)^{n}, 1-\left(1-\mu_{1}^{U}\right)^{n}\right],\left[\left(v_{1}^{L}\right)^{n},\left(v_{1}^{U}\right)^{n}\right]\right), n>0 .
\end{aligned}
$$

Now, we recall the similarity measure of the intuitionistic fuzzy sets. Given $X=\left\{x_{1}, x_{2}, \ldots, x_{n}\right\}$ is a universal set. Let $A=\left\{\left(x_{i}, \mu_{A}\left(x_{i}\right), v_{A}\left(x_{i}\right)\right) \mid x_{i} \in X\right\}, B=\left\{\left(x_{i}, \mu_{B}\left(x_{i}\right), v_{B}\left(x_{i}\right)\right) \mid x_{i} \in X\right\}$ be two IF sets on $X$

Definition 4. (Szmidt \& Kacprzyk, 2004) A mapping S: $\operatorname{IFS}(X) \times \operatorname{IFS}(X) \rightarrow[0,1]$ is a SM of the intuitionistic fuzzy sets if the following conditions are satisfied:

(i) $0 \leq S(A, B) \leq 1, \forall A, B \in I F S(X)$;

(ii) $S(A, B)=S(B, A), \forall A, B \in I F S(X)$;

(iii) $S(A, A)=1, \forall A \in \operatorname{IFS}(X)$.

(iv) For all $A, B, C \in \operatorname{IFS}(X)$ such that $A \subseteq B \subseteq C$ we have $S(A, C) \leq \min \{S(A, B), S(B, C)\}$. 


\section{New similarity measure of the IFSs}

We recall the concept of Hausdorff distance which is important and effective in pattern recognition and classifying problem. For any two intervals $A=\left[a_{1}, a_{2}\right], B=\left[b_{1}, b_{2}\right]$ in the real space, the Hausdorff distance is defined by $H(A, B)=\max \left\{\left|a_{1}-b_{1}\right|,\left|a_{2}-b_{2}\right|\right\}$ (Nadler, 1978; Hung \& Yang, 2004).

The distance and the similarity measure are dual couple. The similarity measure can define via the distance function (Hung \& Yang, 2004). The exponential function has been acknowledged as a useful tool to measure the similarity (Zadeh, 1971; N. R. Pal \& S. K. Pal, 1992). Therefore, motivate by the exponential function and the Hausdorff distance, in this section, we will propose a new similarity which combines them. We also compare our measure with some other ones.

Let $X=\left\{x_{1}, x_{2}, \ldots, x_{n}\right\}$ be a finite set. For $A, B \in \operatorname{IFS}(X)$ we denote $S_{i}^{\mu}(A, B)=e^{-\left|\mu_{A}\left(x_{i}\right)-\mu_{B}\left(x_{i}\right)\right|}$, $S_{i}^{v}(A, B)=1-\left|v_{A}\left(x_{i}\right)-v_{B}\left(x_{i}\right)\right|(i=1,2, \ldots, n)$.

Definition 5. We define a mapping $S_{0}: \operatorname{IFS}(X) \times \operatorname{IFS}(X) \rightarrow[0,1]$ by

$$
\mathrm{S}_{0}(A, B)=\frac{1}{n} \sum_{i=1}^{n} S_{i}^{\mu}(A, B) \times S_{i}^{\nu}(A, B) .
$$

Theorem 1. The function $\mathrm{S}_{0}(A, B)$ in Eq. (1) is a new similarity measure on $\operatorname{IFS}(X)$.

\section{Proof.}

(i) We have $0 \leq S_{i}^{\mu}(A, B)=e^{-\left|\mu_{A}\left(x_{i}\right)-\mu_{B}\left(x_{i}\right)\right|} \leq 1,0 \leq S_{i}^{\nu}(A, B)=1-\left|v_{A}\left(x_{i}\right)-v_{B}\left(x_{i}\right)\right| \leq 1$ for all $A, B \in \operatorname{IFS}(X)$. So that

$$
0 \leq \mathrm{S}_{0}(A, B)=\frac{1}{n} \sum_{i=1}^{n} S_{i}^{\mu}(A, B) \times S_{i}^{v}(A, B) \leq 1 \text { for all } A, B \in \operatorname{IFS}(X) .
$$

(ii) It is obvious.

(iii) For all $A, B \in \operatorname{IFS}(X)$. If $A=B$ then $\mu_{A}\left(x_{i}\right)=\mu_{B}\left(x_{i}\right), v_{A}\left(x_{i}\right)=v_{B}\left(x_{i}\right)$. We have $S_{i}^{\mu}(A, B)=1, S_{i}^{v}(A, B)=1$ and $S_{0}(A, B)=\frac{1}{n} \sum_{i=1}^{n} S_{i}^{\mu}(A, B) \times S_{i}^{v}(A, B)=1$.

(iv) For all $A, B, C \in \operatorname{IFS}(X)$ such that $\mathrm{A} \subseteq \mathrm{B} \subseteq \mathrm{C}$ then $\mu_{A}\left(x_{i}\right) \leq \mu_{B}\left(x_{i}\right) \leq \mu_{C}\left(x_{i}\right)$ and $v_{C}\left(x_{i}\right) \leq v_{B}\left(x_{i}\right) \leq v_{A}\left(x_{i}\right)$. This implies

and

$$
\max \left\{\left|\mu_{A}\left(x_{i}\right)-\mu_{B}\left(x_{i}\right)\right|,\left|\mu_{B}\left(x_{i}\right)-\mu_{C}\left(x_{i}\right)\right|\right\} \leq\left|\mu_{A}\left(x_{i}\right)-\mu_{C}\left(x_{i}\right)\right|
$$

$$
\max \left\{\left|v_{A}\left(x_{i}\right)-v_{B}\left(x_{i}\right)\right|,\left|v_{B}\left(x_{i}\right)-v_{C}\left(x_{i}\right)\right|\right\} \leq\left|v_{A}\left(x_{i}\right)-v_{C}\left(x_{i}\right)\right| .
$$

Then we have

and

$$
\min \left\{-\left|\mu_{A}\left(x_{i}\right)-\mu_{B}\left(x_{i}\right)\right|,-\left|\mu_{B}\left(x_{i}\right)-\mu_{C}\left(x_{i}\right)\right|\right\} \geq-\left|\mu_{A}\left(x_{i}\right)-\mu_{C}\left(x_{i}\right)\right|
$$

$$
\min \left\{-\left|v_{A}\left(x_{i}\right)-v_{B}\left(x_{i}\right)\right|,-\left|v_{B}\left(x_{i}\right)-v_{C}\left(x_{i}\right)\right|\right\} \geq-\left|v_{A}\left(x_{i}\right)-v_{C}\left(x_{i}\right)\right| .
$$

Hence,

$$
S_{i}^{\mu}(A, C) \leq \min \left\{S_{i}^{\mu}(A, B), S_{i}^{\mu}(B, C)\right\} \text { and } S_{i}^{\nu}(A, C) \leq \min \left\{S_{i}^{\nu}(A, B), S_{i}^{\nu}(B, C)\right\} \text {. }
$$


Thus

$$
S_{0}(A, C) \leq \min \left\{S_{0}(A, B), S_{0}(B, C)\right\}
$$

Now, we can define the similarity measure of the IF sets that assigned with the weight of each element in the universal set.

We assume that each element $x_{i}$ in the universal $X=\left\{x_{1}, x_{2}, \ldots, x_{n}\right\}$ is assigned with a weight $\omega_{i} \in[0,1](i=1,2, \ldots, n)$ such that $\sum_{i=1}^{n} \omega_{i}=1$.

Definition 6. We define a mapping $S_{0}^{\omega}: \operatorname{IFS}(X) \times \operatorname{IFS}(X) \rightarrow[0,1]$ by

$$
\mathrm{S}_{0}^{\omega}(A, B)=\sum_{i=1}^{n} \omega_{i} S_{i}^{\mu}(A, B) \times S_{i}^{\nu}(A, B)
$$

Theorem 2. The function $S_{0}^{\omega}(A, B)$ in Eq. (2) is a new similarity measure on $\operatorname{IFS}(X)$.

\section{Proof.}

(i) Because $0 \leq S_{i}^{\mu}(A, B), S_{i}^{v}(A, B) \leq 1$, we have

$0 \leq \mathrm{S}_{0}^{\omega}(A, B)=\sum_{i=1}^{n} \omega_{i} S_{i}^{\mu}(A, B) \times S_{i}^{\nu}(A, B) \leq \sum_{i=1}^{n} \omega_{i}=1$.

(ii) It is obvious.

(iii) If $A=B$ then $\mu_{A}\left(x_{i}\right)=\mu_{B}\left(x_{i}\right), v_{A}\left(x_{i}\right)=v_{B}\left(x_{i}\right)$. We have $S_{i}^{\mu}(A, B)=1, S_{i}^{v}(A, B)=1$.

So that $\mathrm{S}_{0}^{\omega}(A, B)=\sum_{i=1}^{n} \omega_{i} S_{i}^{\mu}(A, B) \times S_{i}^{v}(A, B)=\sum_{i=1}^{n} \omega_{i}=1$.

(iv) For all $A, B, C \in \operatorname{IFS}(X)$ such that $\mathrm{A} \subseteq \mathrm{B} \subseteq \mathrm{C}$

$S_{i}^{\mu}(A, C) \leq \min \left\{S_{i}^{\mu}(A, B), S_{i}^{\mu}(B, C)\right\}$ and $S_{i}^{\nu}(A, C) \leq \min \left\{S_{i}^{\nu}(A, B), S_{i}^{\nu}(B, C)\right\}$.

Hence $S_{0}^{\omega}(A, C)=\sum_{i=1}^{n} \omega_{i} S_{i}^{\mu}(A, C) \times S_{i}^{v}(A, C)$

$\leq \sum_{i=1}^{n} \omega_{i} \min \left\{S_{i}^{\mu}(A, B) \times S_{i}^{\nu}(A, B), S_{i}^{\mu}(B, C) \times S_{i}^{\nu}(B, C)\right\}$

$\leq \sum_{i=1}^{n} \omega_{i} \min \left\{S_{i}^{\mu}(A, B) \times S_{i}^{\nu}(A, B), S_{i}^{\mu}(B, C) \times S_{i}^{\nu}(B, C)\right\}=\min \left\{S_{0}^{\omega}(A, B), S_{0}^{\omega}(B, C)\right\}$.

Example 1. Suppose that $A$ and $B$ are two IFSs in $X=\left\{x_{1}, x_{2}, x_{3}, x_{4}\right\}$ where

$$
\begin{aligned}
& A=\left\{\left(x_{1}, 0.3,0.4\right),\left(x_{2}, 0.9,0.05\right),\left(x_{3}, 0.7,0.2\right),\left(x_{4}, 0.6,0.3\right)\right\} \\
& B=\left\{\left(x_{1}, 0.3,0.2\right),\left(x_{2}, 0.7,0.1\right),\left(x_{3}, 0.3,0.6\right),\left(x_{4}, 0.5,0.45\right)\right\} .
\end{aligned}
$$

We have:

$+S_{0}(A, B)=0.687275$;

+ With the weight vector $\omega=(0.35,0.4,0.1,0.15)$, then $S_{0}^{\omega}(A, B)=0.746704$.

Now, we will compare the new similarity measure to other ones. Given $X=\left\{x_{1}, x_{2}, \ldots, x_{n}\right\}$ is a universal set, let $A=\left\{\left(x_{i}, \mu_{A}\left(x_{i}\right), v_{A}\left(x_{i}\right)\right) \mid x_{i} \in X\right\}, B=\left\{\left(x_{i}, \mu_{B}\left(x_{i}\right), v_{B}\left(x_{i}\right)\right) \mid x_{i} \in X\right\}$ be two IF setson $X$. 
We recall some existing similarity measures as follows:

+ The similarity measure of Ye (2011)

$$
C_{1}(A, B)=\frac{1}{n} \sum_{i=1}^{n} \frac{\mu_{A}\left(x_{i}\right) \mu_{B}\left(x_{i}\right)+v_{A}\left(x_{i}\right) v_{B}\left(x_{i}\right)}{\sqrt{\mu_{A}^{2}\left(x_{i}\right)+v_{A}^{2}\left(x_{i}\right)} \sqrt{\mu_{B}^{2}\left(x_{i}\right)+v_{B}^{2}\left(x_{i}\right)}} .
$$

+ The similarity measure of Shi and Ye (2013)

$$
C_{2}(A, B)=\frac{1}{n} \sum_{i=1}^{n} \frac{\mu_{A}\left(x_{i}\right) \mu_{B}\left(x_{i}\right)+v_{A}\left(x_{i}\right) v_{B}\left(x_{i}\right)+\pi_{A}\left(x_{i}\right) \pi_{B}\left(x_{i}\right)}{\sqrt{\mu_{A}^{2}\left(x_{i}\right)+v_{A}^{2}\left(x_{i}\right)+\pi_{A}^{2}\left(x_{i}\right)} \sqrt{\mu_{B}^{2}\left(x_{i}\right)+v_{B}^{2}\left(x_{i}\right)+\pi_{B}^{2}\left(x_{i}\right)}} .
$$

+ The similarity measure of Ye (2016)

$$
\begin{aligned}
& C S_{1}(A, B)=\frac{1}{n} \sum_{i=1}^{n} \cos \left[\frac{\pi}{2} \max \left(\left|\mu_{A}\left(x_{i}\right)-\mu_{B}\left(x_{i}\right)\right|,\left|v_{A}\left(x_{i}\right)-v_{B}\left(x_{i}\right)\right|,\left|\pi_{A}\left(x_{i}\right)-\pi_{B}\left(x_{i}\right)\right|\right)\right] ; \\
& C S_{2}(A, B)=\frac{1}{n} \sum_{i=1}^{n} \cos \left[\frac{\pi}{4}\left(\left|\mu_{A}\left(x_{i}\right)-\mu_{B}\left(x_{i}\right)\right|+\left|v_{A}\left(x_{i}\right)-v_{B}\left(x_{i}\right)\right|+\left|\pi_{A}\left(x_{i}\right)-\pi_{B}\left(x_{i}\right)\right|\right)\right] .
\end{aligned}
$$

However, one can find some drawbacks of the cosine similarity measure as follows:

Example 2. On the universal set $X=\left\{x_{1}, x_{2}\right\}$, we consider $A=\left\{\left(x_{1}, 0.5,0\right),\left(x_{2}, 0,0\right)\right\}$, $B=\left\{\left(x_{1}, 1,0\right),\left(x_{2}, 1,0\right)\right\}$ and $C=\left\{\left(x_{1}, 0.5,0.5\right),\left(x_{2}, 0,1\right)\right\}$.

It is obviously that $C_{1}(A, B), C_{1}(A, C)$ are not determine. Moreover, we easy see that $C \subset A \subset B$. This implies $C_{2}(B, C) \leq \min \left\{C_{2}(A, B), C_{2}(A, C)\right\}$, but we have $C_{2}(B, C)=\frac{\sqrt{0.5}}{2}$, $C_{2}(A, B)=\frac{\sqrt{0.5}}{2}$ and $C_{2}(A, C)=\frac{0.5}{2}=0.25$. It means

$$
C_{2}(B, C)=\sqrt{0.5}>\min \left\{C_{2}(A, B), C_{2}(A, C)\right\}=0.5 .
$$

Thus the measure of Shi and Ye (2013) does not satisfy the condition (iv) in Definition 4 (Section 2).

Meanwhile, using the proposed new measure in Eq. (1) we have $S_{0}(B, C)=0.1516$, $S_{0}(A, C)=0.25$ and $S_{0}(A, B)=0.4872$ which satisfies $C_{2}(B, C) \leq \min \left\{C_{2}(A, B), C_{2}(A, C)\right\}$.

In the pattern recognition, there are two patterns $A_{1}, A_{2}$ and a sample $B$. If $S\left(A_{1}, B\right)<S\left(A_{2}, B\right)$ then we put $B$ belongs to pattern $A_{2}$. We consider the following example:

Example 3. On the universal set $X=\left\{x_{1}, x_{2}\right\}$, we consider two patterns $A_{1}, A_{2}$ as follows $A_{1}=\left\{\left(x_{1}, 0.5,0\right),\left(x_{2}, 0,0\right)\right\}, A_{2}=\left\{\left(x_{1}, 0.5,0.5\right),\left(x_{2}, 0,1\right)\right\}$ and a sample $B=\left\{\left(x_{1}, 1,0\right),\left(x_{2}, 1,0\right)\right\}$.

\section{Question: which sample $B$ belongs to?}

If we follow the similarity measure of Ye (2016) then

$$
C S_{1}\left(B, A_{1}\right)=C S_{1}\left(B, A_{2}\right)=\frac{\sqrt{0.5}}{2}, C S_{2}\left(B, A_{1}\right)=C S_{2}\left(B, A_{2}\right)=\frac{\sqrt{0.5}}{2} \text {. }
$$

These do not show $B$ belongs to pattern $A_{1}$ or $A_{2}$. On the other hand, if using our method in Equation (2), then we have $S_{0}\left(B, A_{2}\right)=0.1516, S_{0}\left(B, A_{1}\right)=0.4872$ and thus $B$ belongs to pattern $A_{1}$. This is justified because $A_{2} \subset A_{1} \subset B$.

The above examples show the advantages of the new measure in this paper compared to some previous measures. 


\section{The similarity measure of the IVIFSs}

We will extend our method to the IVIFSs in this section. Let $A$ and $B$ be two arbitrary IVIFSs in $X$ as follows:

$$
\begin{aligned}
& A=\left\{\left(x_{i},\left[\mu_{A}^{L}\left(x_{i}\right), \mu_{A}^{U}\left(x_{i}\right)\right],\left[v_{A}^{L}\left(x_{i}\right), v_{A}^{U}\left(x_{i}\right)\right]\right) \mid x_{i} \in X\right\} ; \\
& B=\left\{\left(x_{i},\left[\mu_{B}^{L}\left(x_{i}\right), \mu_{B}^{U}\left(x_{i}\right)\right],\left[v_{B}^{L}\left(x_{i}\right), v_{B}^{U}\left(x_{i}\right)\right]\right) \mid x_{i} \in X\right\} . \\
& \text { For } s, t \in \mathrm{N}=\{0,1,2, \ldots\}, \text { we denote } \\
& S_{i}^{\mu}(A, B)=e \frac{-\left|\mu_{A}^{L}\left(x_{i}\right)-\mu_{B}^{L}\left(x_{i}\right)\right|^{s}-\left|\mu_{A}^{U}\left(x_{i}\right)-\mu_{B}^{U}\left(x_{i}\right)\right|^{s}}{2} \\
& S_{i}^{v}(A, B)=1-\frac{\left|v_{A}^{L}\left(x_{i}\right)-v_{B}^{L}\left(x_{i}\right)\right|^{t}+\left|v_{A}^{U}\left(x_{i}\right)-v_{B}^{U}\left(x_{i}\right)\right|^{t}}{2} \text { for all } i=1,2, \ldots, n .
\end{aligned}
$$

Definition 7. We define the similarity measure of two intervals IF $A$ and $B$ as follows

$$
S_{s, t}^{\omega}(A, B)=\frac{1}{n} \sum_{i=1}^{n} S_{i}^{\mu}(A, B) \times S_{i}^{v}(A, B) .
$$

Theorem 3. Let $A$ and $B$ be two arbitrary IVIFSs on $X$. We have

(i) $0 \leq S_{s, t}^{\omega}(A, B) \leq 1, \forall A, B \in \operatorname{IVIFS}(X)$;

(ii) $S_{s, t}^{\omega}(A, B)=S_{s, t}^{\omega}(B, A), \forall A, B \in \operatorname{IVIFS}(X)$;

(iii) $S_{s, t}^{\omega}(A, A)=1, \forall A \in \operatorname{IVIFS}(X)$;

(iv) For all $A, B, C \in I V I F S(X)$ such that $A \subseteq B \subseteq C$ we have $S_{s, t}^{\omega}(A, C) \leq S_{s, t}^{\omega}(A, B)$ and $S_{s, t}^{\omega}(A, C) \leq S_{s, t}^{\omega}(B, C)$.

Proof. It is easy.

In the case, each element $x_{i}$ in the universal $X=\left\{x_{1}, x_{2}, \ldots, x_{n}\right\}$ is assigned with a weight $\omega_{i} \in[0,1](i=1,2, \ldots, n)$ and $\sum_{i=1}^{n} \omega_{i}=1$ then the similarity measure of $A$ and $B$ is defined by:

Definition 8. We define the similarity measure of two intervals IF $A$ and $B$ as follows

$$
\mathrm{S}_{s, t}^{\omega}(A, B)=\sum_{i=1}^{n} \omega_{i} S_{i}^{\mu}(A, B) \times S_{i}^{\nu}(A, B) .
$$

Remark. It is easy to show that the SM of $A$ and $B$ in the Definition 8 satisfies all the conditions of the Theorem 3.

Example 4. We consider a pattern recognition problem about the classification of minerals; the data was quoted from Liu et al. (2016). There are three classes of given minerals, which are expressed by the IVIFSs $A_{1}, A_{2}, A_{3}$ in the feature space $X=\left\{x_{1}, x_{2}, x_{3}, x_{4}, x_{5}, x_{6}\right\}$. Assume there is a new mineral $A$ along with its known attribute values. Our aim is to determine which class that $A$ belongs to. The descriptive data information is given in Table 1 . According to the Table 2, we can comment that the similarity measure between $A_{i}(i=1,2,3)$ and $A$ with $\omega=\left(\frac{1}{6}, \frac{1}{6}, \frac{1}{6}, \frac{1}{6}, \frac{1}{6}, \frac{1}{6}\right)$ is $S\left(A_{3}, A\right)>S\left(A_{1}, A\right)>S\left(A_{2}, A\right)$, so $A$ belongs to class $A_{3}$. 
Table 1. Data information of minerals

\begin{tabular}{|c|c|c|c|c|}
\hline & $A_{1}$ & $A_{2}$ & $A_{3}$ & $\mathrm{~A}$ \\
\hline$x_{1}$ & $([0.72,0.74],[0.1,0.12])$ & $([0.42,0.45],[0.38,0.40])$ & $([0.30,0.32],[0.45,0.47])$ & $([0.60,0.63],[0.30,0.35])$ \\
\hline$x_{2}$ & $([0.00,0.05],[0.80,0.82])$ & $([0.65,0.67],[0.28,0.30])$ & $([0.90,1.00],[0.00,0.00])$ & $([0.50,0.53],[0.34,0.36])$ \\
\hline$x_{3}$ & $([0.18,0.20],[0.62,0.63])$ & $([0.00,1.00],[0.00,0.00])$ & $([0.18,0.20],[0.70,0.73])$ & $([0.20,0.21],[0.68,0.70])$ \\
\hline$x_{4}$ & $([0.49,0.50],[0.35,0.37])$ & $([0.70,0.90],[0.00,0.10])$ & $([0.15,0.16],[0.75,0.78])$ & $([0.20,0.22],[0.75,0.77])$ \\
\hline$x_{5}$ & $([0.01,0.02],[0.60,0.63])$ & $([0.80,1.00],[0.00,0.00])$ & $([0.00,0.05],[0.88,0.90])$ & $([0.05,0.07],[0.87,0.90])$ \\
\hline$x_{6}$ & $([0.72,0.74],[0.12,0.13])$ & $([0.90,1.00],[0.00,0.00])$ & $([0.65,0.68],[0.25,0.30])$ & $([0.65,0.70],[0.25,0.30])$ \\
\hline
\end{tabular}

Table 2. The similarity measure between $A_{i}(i=1,2,3)$ and $A$

\begin{tabular}{|l|c|c|c|}
\hline & $S\left(A_{1}, A\right)$ & $S\left(A_{2}, A\right)$ & $S\left(A_{3}, A\right)$ \\
\hline The similarity using Eq.(3) & 0.583615 & 0.353333 & 0.744232 \\
\hline
\end{tabular}

Table 3. Correlation coefficients between $A_{i}(i=1,2,3)$ and $A$ under different methods

\begin{tabular}{|l|c|c|c|}
\hline & $\rho\left(A_{1}, A\right)$ & $\rho\left(A_{2}, A\right)$ & $\rho\left(A_{3}, A\right)$ \\
\hline Method in Li \& Cheng, 2002 & 0.53 & -0.52 & 0.81 \\
\hline Method in Bustince \& Burillo, 1995 & 0.86 & 0.52 & 0.94 \\
\hline Method in Shidpour, Bernard \& Shahrokhi, 2013 & 0.78 & 0.77 & 0.84 \\
\hline Method in Hung, 2001 & 0.52 & -0.53 & 0.81 \\
\hline Method in Buhaesku, 1998 & 0.85 & 0.51 & 0.94 \\
\hline
\end{tabular}

We also compare the result of our method to the results obtained by other methods in $\mathrm{Li}$ and Cheng (2002), Bustince and Burillo (1995), Shidpour, Bernard, and Shahrokhi (2013), Hung (2001) and Buhaesku (1988) (see Table 3). Our result is identical with the results using these methods.

\section{Multi-criteria decision making model}

In the MCDM problem, the decision makers are responsible for choosing the best suitable option from the set of alternatives. They must assess alternatives under criteria. The criterion outcomes are a basis to rank the options (Kelemenis \&Askounis, 2010). The fundamental process of MCDM model includes the following steps (Kelemenis \& Askounis, 2010; Shen, Olfat, Govindan, Khodaverdi \& Diabat, 2013):

Step 1. Construct the decision matrix.

Step 2. Determine the matrix of the criteria weight.

Step 3. Construct the weighted decision matrix.

Step 4. Rank the alternatives.

The object of this section is applying the similarity measure for the interval-valued intuitionistic fuzzy sets to construct a novel MCDM model.

Let $\left\{P_{i}(i=1,2, \ldots, m)\right\}$ be a set of alternatives for evaluation, $C_{j}(j=1,2, \ldots, n)$ be $\mathrm{n}$ criteria to select the optimal option. There are h decision makers (DMs) $D_{t}(t=1,2, \ldots, h)$ to identify 
the importance of criteria and the meeting criteria of alternatives through the linguistic terms given in the Table 4 and Table 5. The SM of the interval-valued IF sets is used to rank the alternatives. The model has the following steps:

Table 4. The intuitionistic rating scale for important degree

\begin{tabular}{|l|c|}
\hline \multicolumn{1}{|c|}{ Linguistic scale for important degree } & Interval intuitionistic fuzzy scale \\
\hline Unimportant (UI) & $([0.2,0.3],[0.5,0.6])$ \\
\hline Ordinary Important (OI) & $([0.3,0.4],[0.4,0.5])$ \\
\hline Important (I) & $([0.5,0.6],[0.3,0.4])$ \\
\hline Very Important (VI) & $([0.7,0.8],[0.1,0.2])$ \\
\hline Absolutely Important (AI) & $([0.8,0.9],[0,0.1])$ \\
\hline
\end{tabular}

Table 5. The intuitionistic rating scale

\begin{tabular}{|l|c|}
\hline Linguistic scale for perform an alternatives & Interval intuitionistic fuzzy scale \\
\hline Very low $(\mathrm{VL})$ & $([0.1,0.2],[0.6,0.7])$ \\
\hline Low $(\mathrm{L})$ & $([0.3,0.4],[0.5,0.6])$ \\
\hline Fair $(\mathrm{F})$ & $([0.4,0.5],[0.4,0.5])$ \\
\hline Good $(\mathrm{G})$ & $([0.6,0.7],[0.2,0.3])$ \\
\hline Very good $(\mathrm{VG})$ & $([0.7,0.8],[0.1,0.2])$ \\
\hline
\end{tabular}

Step 1. Determine the weight vector $\omega_{j}$ of the criterion $C_{j}(j=1,2, \ldots, n)$.

Each of criterion has a different importance, which is made by the DMs. Assume that the aggregated weight of the criterion $C_{j}$ is represented by $\omega_{j}=\left(\left[a_{\mathrm{j}}, b_{\mathrm{j}}\right],\left[c_{\mathrm{j}}, d_{\mathrm{j}}\right]\right)$.

Step 2. Evaluate the performance of the alternative $P_{i}$ under the criterion $C_{j}$.

The DMs appraise alternatives with respect to all criteria. The aggregated value of each alternative is expressed by the interval-valued intuitionistic fuzzy number $P_{i j}=\left(\left[\mu^{L}{ }_{\mathrm{ij}}, \mu^{U}{ }_{\mathrm{ij}}\right],\left[\nu_{\mathrm{ij}}^{L}, v_{\mathrm{ij}}^{U}\right]\right), i=1,2, \ldots, m ; j=1,2, \ldots, n$.

The criteria are divided into two types, benefit or cost, therefore the cost criteria need to be transformed into benefit type. The $P_{i j}$ is converted to the standardized value $r_{i j}$ by $r_{i j}=P_{i j}$ if $C_{j}$ is benefit type, $r_{i j}=P_{i j}^{c}$ if $C_{j}$ is cost type (According to Xu \& Hu, 2010).

Step 3. Determine the overall values of alternatives

The overall value of each alternative with respect to each criterion is multiple of the value $r_{i j}$ with the aggregated weight $\omega_{j}$

$$
V_{i j}=r_{i j} \otimes \omega_{j}, i=1,2, \ldots, m ; j=1,2, \ldots, n \text {. (According to Shen et al., 2013). }
$$

Step 4. Rank the alternatives

In order to identify the optimal alternative, all alternatives need to be compared with the ideal solution $P_{b}=([1,1],[0,0])$. The alternatives are ranked via the similarity measure

$$
S_{i}=\frac{1}{n} \sum_{j=1}^{n} S_{i}^{\mu}\left(V_{i j}, P_{b}\right) \times S_{i}^{\nu}\left(V_{i j}, P_{b}\right),(i=1,2, \ldots, m) .
$$

Following the property of the similarity measure, the alternative $A_{i}$ is better than the alternative $A_{k}$ if $S_{i}>S_{k}, i=1,2, \ldots, m$ and $k=1,2, \ldots, m$. 


\section{Case study}

In this section, a case study was performed in a well-known company in Vietnam, which is a joint venture company between Japan, Thailand and Vietnam covertures. This company has grown rapidly and become one of the leading companies in the automobile and motorcycles sector. The company put an acute focus into providing customers with high quality products at reasonable prices. The managers of this company involve how to select the target market to gain outstanding profit. In order to determine the most suitable market, we conducted a survey on target market research. The four market segments defined as alternatives were denoted by $\mathrm{SE}_{1}, \mathrm{SE}_{2}, \mathrm{SE}_{3}$, and $\mathrm{SE}_{4}$. The data used as input for evaluated process was collected by interview the experts. This group includedthe marketing manager, the sales manager, the experts in business and the expert in university.

Simkin and Dibb (1998) carried out a survey of the criteria for selecting target markets. They referredfrom literature and interviewed with experts. As a result, Identify profitability (C1), The growth of the market (C2), Size of market (C3), likely customer satisfaction (C4), sales volume (C5), Likelihood of sustainable differential advantage (C6), Development opportunities (C7) and The differentiation of product (C8) were most heavily-used criteria. The experts recognized that these criteria were suitable in Vietnam's market. In this section, we will use these criteria to select the target market. The procedure is represented as follow:

Step 1. Determining the weight of criterion.

After defining the criteria, the experts were asked to determine the important degree of each criterion using the scale for importance. Based on the opinion of experts for each criterion, we calculated their averaged values. The weight of each criterion is shown in the Table 6 .

Step 2. Evaluating the performance of the market segment with respect to the criterion.

Four experts are responsible for evaluating the degree of satisfying of alternatives respect to the criteria. Their opinions were expressed through the interval intuitionistic fuzzy numbers, which is shown in the Table 5. The averaged values are assigned by the decision makers for markets under the criteria is shown in the Table 7.

Table 6. The weight of criterion

\begin{tabular}{|c|c|c|c|c|c|}
\hline Criteria & \multicolumn{4}{|c|}{ Decision makers $\left(D_{1}-D_{4}\right)$} & Averaged values \\
\hline$C_{1}$ & AI & $\mathrm{AI}$ & AI & AI & $([0.8,0.9],[0,0.1])$ \\
\hline$C_{2}$ & VI & VI & VI & I & $([0.659,0.762],[0.132,0.238])$ \\
\hline$C_{3}$ & VI & I & VI & VI & $([0.659,0.762],[0.132,0.238])$ \\
\hline$C_{4}$ & OI & I & I & I & $([0.456,0.557],[0.322,0.423])$ \\
\hline$C_{5}$ & I & I & OI & OI & $([0.408,0.510],[0.346,0.447])$ \\
\hline$C_{6}$ & $\mathrm{I}$ & $\mathrm{I}$ & $\mathrm{I}$ & $\mathrm{I}$ & $([0.5,0.6],[0.3,0.4])$ \\
\hline$C_{7}$ & I & $\mathrm{I}$ & VI & VI & $([0.613,0.717],[0.173,0.283])$ \\
\hline$C_{8}$ & I & I & I & I & $([0.5,0.6],[0.3,0.4])$ \\
\hline
\end{tabular}

In this case, all the criteria used for evaluation are the criteria of benefit. Therefore, it is not necessary to convert to the standardized values. 
Step 3. Determining the overall values of market segments.

The overall value of each market segment with respect to each criterion is calculated by the Equation (5), it is shown in the last column of the Table 7.

Step 4. Calculating the similarity measure $S_{i}$ of each market by Eq. (6) with $s=t=1$.

Ranking of markets based on the similarity measure. The result is shown in the Table 8 and Figure 1.

Table 7. The interval-valued intuitionistic fuzzy decision matrix

\begin{tabular}{|c|c|c|c|c|c|c|c|}
\hline $\begin{array}{l}\text { Seg- } \\
\text { ment }\end{array}$ & \multirow{2}{*}{$\begin{array}{c}\begin{array}{c}\text { Crite- } \\
\text { ria }\end{array} \\
C_{1} \\
\end{array}$} & \multicolumn{4}{|c|}{ Decision makers } & \multirow{2}{*}{$\begin{array}{c}\text { Averaged values } \\
([0,654,0.755],[0.141,0.245])\end{array}$} & \multirow{2}{*}{$\begin{array}{c}\text { Overall values } V_{i j} \\
([0.523,0.68],[0.141,0.321) \\
\end{array}$} \\
\hline \multirow{8}{*}{$S E_{1}$} & & VG & VG & G & G & & \\
\hline & $C_{2}$ & G & G & VG & VG & $([0,654,0.755],[0.141,0.245])$ & $([0.431,0.576],[0.254,0.425])$ \\
\hline & $C_{3}$ & G & VG & G & $\mathrm{F}$ & $([0.588,0.692],[0,200,0.308])$ & $([0.388,0.527],[0.305,0.473])$ \\
\hline & $C_{4}$ & $\mathrm{~F}$ & G & $\mathrm{F}$ & $\mathrm{F}$ & $([0.476,0,56],[0.336,0.440])$ & $([0.209,0.312],[0.550,0.677])$ \\
\hline & $C_{5}$ & G & $\mathrm{F}$ & $\mathrm{F}$ & $\mathrm{F}$ & $([0.476,0,56],[0.336,0.440])$ & $([0.187,0.286],[0.566,0.691])$ \\
\hline & $C_{6}$ & VG & G & VG & VG & $([0.678,0.779],[0.119,0.221])$ & $([0.339,0.467],[0.383,0.533])$ \\
\hline & $C_{7}$ & G & G & VG & $\mathrm{G}$ & $([0,628,0.729],[0.168,0.271])$ & $([0.385,0.523],[0.312,0.477])$ \\
\hline & $C_{8}$ & G & G & VG & VG & $([0.654,0.755],[0.141,0.245])$ & $([0.327,0.453],[0.399,0.547])$ \\
\hline \multirow{8}{*}{$S E_{2}$} & $C_{1}$ & G & $\mathrm{F}$ & $\mathrm{G}$ & $\mathrm{G}$ & $([0,557,0.659],[0.238,0.341])$ & $([0.446,0.593],[0.238,0.407])$ \\
\hline & $\mathrm{C}_{2}$ & G & $\mathrm{F}$ & $\mathrm{F}$ & $\mathrm{F}$ & $([0,458,0.56],[0.336,0.440])$ & $([0.302,0.427],[0.424,0.573])$ \\
\hline & $C_{3}$ & $\mathrm{~F}$ & G & G & $\mathrm{F}$ & $([0.510,0.613],[0.283,0.387])$ & $([0.336,0.467],[0.377,0.533])$ \\
\hline & $C_{4}$ & $\mathrm{~F}$ & $\mathrm{~F}$ & $\mathrm{~F}$ & $\mathrm{~F}$ & $([0.4,0.5],[0.4,0.5])$ & $([0.182,0.279],[0.593,0.712])$ \\
\hline & $C_{5}$ & G & $\mathrm{F}$ & $\mathrm{F}$ & $\mathrm{F}$ & $([0.458,0.56],[0.336,0.440])$ & $([0.187,0.286],[0.566,0.691])$ \\
\hline & $C_{6}$ & G & G & G & $\mathrm{F}$ & $([0.557,0.659],[0,238,0.341])$ & $([0.279,0.396],[0.467,0.605])$ \\
\hline & $C_{7}$ & G & G & $\mathrm{F}$ & $\mathrm{F}$ & $([0.510,0.613],[0.283,0.387])$ & $(0.313,0.439],[0.407,0.561])$ \\
\hline & $C_{8}$ & G & $\mathrm{F}$ & $\mathrm{F}$ & G & $([0.510,0.613],[0.283,0.387])$ & $([0.255,0.368],[0.498,0.632])$ \\
\hline \multirow{8}{*}{$S E_{3}$} & $C_{1}$ & G & G & G & VG & $([0.628,0.729],[0.168,0.271])$ & $([0.502,0.656],[0.168,0.344])$ \\
\hline & $C_{2}$ & VG & VG & VG & VG & $([0.7,0.8],[0.1,0.2])$ & $([0.461,0.61],[0.218,0.390])$ \\
\hline & $C_{3}$ & VG & VG & G & G & $([0.654,0.755],[0.141,0.245])$ & $([0.431,0.576],[0.254,0.425])$ \\
\hline & $C_{4}$ & $\mathrm{G}$ & VG & VG & VG & $([0.678,0.779],[0.119,0.221])$ & $([0.309,0.434],[0.403,0.551])$ \\
\hline & $C_{5}$ & $\mathrm{VG}$ & VG & VG & $\mathrm{VG}$ & $([0.7,0.8],[0.1,0.2])$ & $([0.286,0.408],[0.412,0.558])$ \\
\hline & $C_{6}$ & G & G & VG & G & $([0.673,0.729],[0.228,0.336])$ & $([0.314,0.437],[0.418,0.563])$ \\
\hline & $C_{7}$ & G & G & VG & VG & $([0.654,0.755],[0.141,0.245])$ & $([0.401,0.542],[0.290,0.459])$ \\
\hline & $C_{8}$ & G & VG & VG & G & $([0.654,0.755],[0.141,0.245])$ & $([0.327,0.453],[0.399,0.547])$ \\
\hline \multirow{8}{*}{$S E_{4}$} & $C_{1}$ & VG & VG & G & G & $([0.654,0.755],[0.141,0.245])$ & $([0.523,0.68],[0.141,0.321)$ \\
\hline & $C_{2}$ & $\mathrm{VG}$ & $\mathrm{VG}$ & $\mathrm{G}$ & G & $([0.654,0.755],[0.141,0.245])$ & $([0.431,0.576],[0.254,0.425])$ \\
\hline & $C_{3}$ & G & G & G & VG & $([0,628,0.729],[0.228,0.336])$ & $([0.414,0.556],[0.278,0.444])$ \\
\hline & $C_{4}$ & $\mathrm{~F}$ & $\mathrm{~F}$ & $\mathrm{~F}$ & $\mathrm{~F}$ & $([0.4,0.5],[0.4,0.5])$ & $([0.182,0.279],[0.593,0.712])$ \\
\hline & $C_{5}$ & G & $\mathrm{F}$ & $\mathrm{F}$ & $\mathrm{F}$ & $([0.476,0,56],[0.336,0.440])$ & $([0.187,0.286],[0.566,0.691])$ \\
\hline & $C_{6}$ & VG & VG & G & G & $([0.654,0.755],[0.141,0.245])$ & $([0.327,0.453],[0.399,0.547])$ \\
\hline & $C_{7}$ & $\mathrm{~F}$ & $\mathrm{~F}$ & G & G & $([0.510,0.614],[0.283,0.387])$ & $([0.313,0.439],[0.407,0.561])$ \\
\hline & $C_{8}$ & $\mathrm{~F}$ & $\mathrm{~L}$ & $\mathrm{~L}$ & $\mathrm{~L}$ & $([0.327,0.427],[0.473,0.573])$ & $([0.163,0.256],[0.631,0.744])$ \\
\hline
\end{tabular}




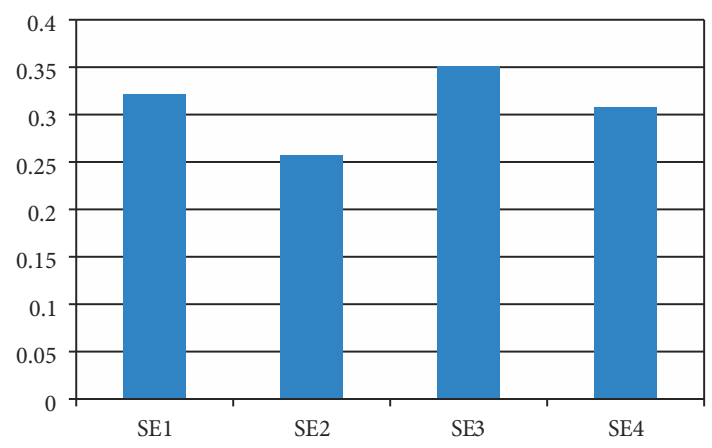

Figure 1 . The similarity measure of four market segments with the best alternative

Table 8 . The result of ranking markets based on the similarity measure

\begin{tabular}{|l|c|c|c|c|}
\hline \multicolumn{1}{|c|}{ The market } & SE1 & SE2 & SE3 & SE4 \\
\hline Similarity measure & 0.32075 & 0.25659 & 0.35034 & 0.30735 \\
\hline Ranking & 2 & 4 & 1 & 3 \\
\hline
\end{tabular}

The ranking between markets is $\mathrm{SE}_{3}, \mathrm{SE}_{1}, \mathrm{SE}_{4}, \mathrm{SE}_{2}$, the target market is $\mathrm{SE}_{3}$.

\section{Discussion}

In order to check our methodas well as measure, we consider the models of Shen et al. (2013); $\mathrm{Xu}$ (2007b); Wei, Wang, and Zhang (2011); the similarity measures of Ye (2011, 2016); Shi and Ye (2013).

In the model of Shen et al. (2013), the TOPSIS method was used to rank the options, the evaluated values were expressed by the triangular fuzzy numbers and the distance function was $d(A, B)=\sqrt{\frac{1}{3}\left[\left(a_{1}-a_{2}\right)^{2}+\left(b_{1}-b_{2}\right)^{2}+\left(c_{1}-c_{2}\right)^{2}\right]}$.

In the model of $\mathrm{Xu}(2007 \mathrm{~b})$, the similarity measure was used in the TOPSIS model to rank the alternatives with $s(A, B)=1-\left[\frac{1}{2 n} \sum_{i=1}^{n}\left|\mu_{i A}-\mu_{i B}\right|^{2}+\left|v_{i A}-v_{i B}\right|^{2}+\left|\pi_{i A}-\pi_{i B}\right|^{2}\right]^{1 / 2}, \pi_{i}=1-\mu_{i}-v_{i}$. The evaluated values used the intuitionistic fuzzy numbers.

In the model of Wei et al. (2011), the similarity measure was used in the TOPSIS model to rank the alternatives with $s(A, B)=\frac{1}{n} \sum_{i=1}^{n} \frac{2-\min \left\{u_{i}^{-}, v_{i}^{-}\right\}-\min \left\{u_{i}^{+}, v_{i}^{+}\right\}}{2+\min \left\{u_{i}^{-}, v_{i}^{-}\right\}+\min \left\{u_{i}^{+}, v_{i}^{+}\right\}}$in which $u_{i}^{-}=\left|u_{i A}^{L}-u_{i B}^{L}\right|, u_{i}^{+}=\left|u_{i A}^{U}-u_{i B}^{U}\right|, v_{i}^{-}=\left|v_{i A}^{L}-v_{i B}^{L}\right|, v_{i}^{+}=\left|v_{i A}^{U}-v_{i B}^{U}\right|$. The interval-valued intuitionistic fuzzy numbers were used to represent the evaluated values.

The similarity measures of Ye $(2011,2016)$, Shi and Ye (2013) were used to arrange the order of alternatives. The results of ranking are shown in the Table 9. 
Table 9. The results of ranking of different methods

\begin{tabular}{|l|c|}
\hline \multicolumn{1}{|c|}{ Methods } & Ranking order results \\
\hline Xu (2007b)'s method & $S E_{3}, S E_{1}, S E_{4}, S E_{2}$ \\
\hline Shen et al. (2013)'s method & $S E_{3}, S E_{1}, S E_{4}, S E_{2}$ \\
\hline Ye (2011)'s measure & $S E_{3}, S E_{1}, S E_{4}, S E_{2}$ \\
\hline Shi and Ye (2013)'s measure & $S E_{3}, S E_{1}, S E_{4}, S E_{2}$ \\
\hline Ye (2016)'s measure & $S E_{3}, S E_{1}, S E_{4}, S E_{2}$ \\
\hline Proposed method & $S E_{3}, S E_{1}, S E_{4}, S E_{2}$ \\
\hline Wei et al (2011)'s method & $S E_{1}, S E_{3}, S E_{4}, S E_{2}$ \\
\hline
\end{tabular}

The result of our method is as same as with the methods of Xu (2007b), Shen et al. (2013), Ye $(2011,2016)$ and Shi and Ye (2013) There is a little difference between the ranking in the method of Wei et al. (2011)and the rest of methods. On the other hand, based on the evaluation of the decision makers in the third column of the Table 7, the $S E_{3}$ is better than the $S E_{1}$ in the almost of criteria. Thus, the ranking $S E_{3}, S E_{1}, S E_{4}, S E_{2}$ is reliable.

\section{Conclusions}

In current markets, the businesses have to face a lot of challenges due to the development of new technologies, competitors and customers evolving trends. The target market is the center of the marketing decisions. It helps the firms provide suitable marketing strategies. In this article, we have introduced some formulas that define the similarity measures between intuitionistic fuzzy sets and interval-valued intuitionistic fuzzy sets. A multi-criteria decision making method is proposed under intuitionistic fuzzy environment to select the best alternatives. Finally, a case study for selecting the target market was performed. The similarity measures are new and convenient for applications. Our model can be used to rank alternatives in other fields.

\section{Acknowledgements}

This research is funded by Vietnam National Foundation for Science and Technology Development (NAFOSTED) under grant number 502.01 - 2018.09.

\section{References}

Aghdaie, M. H., Zolfani, S. H., \& Zavadskas, E. K. (2013). Market segment evaluation and selection based on application of fuzzy AHP and COPRAS-G methods. Journal of Business Economics and Management, 14, 213-233. https://doi.org/10.3846/16111699.2012.721392

Aghdaie, M. H. (2015). Target market selection based on market segment evaluation: a multiple attribute decision making approach. International Journal Operational Research, 24, 262-278.

https://doi.org/10.1504/IJOR.2015.072231 
Atanassov, K. T. (1986). Intuitionistic fuzzy sets. Fuzzy Sets and Systems, 20(1), 87-96. https://doi.org/10.1016/S0165-0114(86)80034-3

Atanassov, K. T., \& Gargov, G. (1989). Interval valued intuitionistic fuzzy sets. Fuzzy Sets and Systems, 31(3), 343-349. https://doi.org/10.1016/0165-0114(89)90205-4

Bernstein, J. S. (2014). Marketing insights for engaging performing arts audiences. New York: Palgrave Macmillan.

Bharati, S. K., \& Singh, S. R. (2014). Intuitionistic fuzzy optimization technique in agricultural production planning: A small farm holder perspective. International Journal of Computer Applications, 89(6), 17-23. https://doi.org/10.5120/15507-4276

Buhaesku, T. (1988). On the convexity of intuitionistic fuzzy sets. In Itinerant Seminar of Functional Equations, Approximation and Convexity (pp. 137-144). Cluj-Napoca.

Bustince, H., \& Burillo, P. (1995). Correlation of interval-valued intuitionistic fuzzy sets. Fuzzy Sets and Systems, 74(2), 237-244. https://doi.org/10.1016/0165-0114(94)00343-6

Chiang, D. A., \& Lin, N. P. (1999). Correlation of fuzzy sets. Fuzzy Sets and Systems, 102(2), 221-226. https://doi.org/10.1016/S0165-0114(97)00127-9

Chiu, C.-Y., Chen, Y.-F., \& Kuo, I.-T. K. (2009). An intelligent market segmentation system using kmeans and particle swarm optimization. Expert Systems with Applications, 36, 4558-4565. https://doi.org/10.1016/j.eswa.2008.05.029

Gerstenkorn, T., \& Mańko, J. (1991). Correlation of intuitionistic fuzzy sets. Fuzzy Sets and Systems, 44(1), 39-43. https://doi.org/10.1016/0165-0114(91)90031-K

Hung, W. L. (2001). Using statistical viewpoint in developing correlation of intuitionistic fuzzy sets. International Journal of Uncertainty, Fuzziness and Knowledge-Based Systems, 9(4), 509-516. https://doi.org/10.1142/S0218488501000910

Hung, W. L., \& Wu, J. W. (2002). Correlation of intuitionistic fuzzy sets by centroid method. Information Sciences, 144(1), 219-225. https://doi.org/10.1016/S0020-0255(02)00181-0

Hung, W. L., \& Yang, M. S. (2004). Similarity measure of intuitionistic fuzzy sets based on Hausdorff distance. Pattern Recognition Letters, 25, 1603-1611. https://doi.org/10.1016/j.patrec.2004.06.006

Hwang, C. M., Yang, M. S., Hung, W. L., \& Lee, M. G. (2012). A similarity measure of intuitionistic fuzzy sets based on the Sugeno integral with its application to pattern recognition. Information Sciences, 189, 93-109. https://doi.org/10.1016/j.ins.2011.11.029

Kelemenis, A., \& Askounis, D. (2010). A new TOPSIS-based multi-criteria approach for personal selection. Expert Systems with Applications, 37, 4999-5008. https://doi.org/10.1016/j.eswa.2009.12.013

Kotler, P., \& Armstrong, G. (2003). Principles of marketing (10 ${ }^{\text {th }}$ ed.). Upper Saddle River, NJ: PrenticeHall.

Kotler, P. (1980). Marketing management - analysis, planning, and control (4th ed.). Upper Saddle River, NJ: Prentice-Hall.

Kuo, R. J., Ho, L. M., \& Hu, C. M. (2002). Integration of self-organizing feature map and K-meansalgorithm for market segmentation. Computers and Operations Research, 29, 1475-1493. https://doi.org/10.1016/S0305-0548(01)00043-0

Li, D., \& Cheng, C. (2002). New similarity measures of intuitionistic fuzzy sets and application to pattern recognition. Pattern Recognition Letters, 23, 221-225. https://doi.org/10.1016/S0167-8655(01)00110-6

Li, J., \& Zeng, W. (2015). A new dissimilarity measure between intuitionistic fuzzy sets and its application in multiple attribute decision making. Journal of Intelligent \& Fuzzy Systems, 29(4), 1311-1320. https://doi.org/10.3233/IFS-141440 
Liang, Z., \& Shi, P. (2003). Similarity measures on intuitionistic fuzzy sets. Pattern Recognition Letters, 24(15), 2687-2693. https://doi.org/10.1016/S0167-8655(03)00111-9

Liu, B., Shen, Y., Mu, L., Chen, X., \& Chen, L. (2016). A new correlation measure of the intuitionistic fuzzy sets. Journal of Intelligent \& Fuzzy Systems, 30(2), 1019-1028. https://doi.org/10.3233/IFS-151824

Mitchell, H. B. (2004). A correlation coefficient for intuitionistic fuzzy sets. International Journal of Intelligent Systems, 19(5), 483-490. https://doi.org/10.1002/int.20004

Nadler Jr., S. B. (1978). Hyperspaces of sets. New York: Marcel Dekker.

Pal, N. R., \& Pal, S. K. (1992). Some properties of the exponential entropy. Information Sciences, 66, 119-137. https://doi.org/10.1016/0020-0255(92)90090-U

Park, J. H., Hwang, J. H., Park, W. J., Wei, H., \& Lee, S. H. (2013). Similarity measure on intuitionistic fuzzy sets. Journal of Central South University, 20(8), 2233-2238. https://doi.org/10.1007/s11771-013-1729-y

Simkin, L., \& Dibb, S. (1998). Prioritizing target markets. Marketing Intelligence and Planning, 16, 407417. https://doi.org/10.1108/02634509810244417

Shen, L., Olfat, L., Govindan, K., Khodaverdi, R., \& Diabat, A. (2013). A fuzzy multi criteria approach for evaluating green supplier's performance in green supply chain with linguistic preferences. Resources, Conservation and Recycling, 74, 170-179. https://doi.org/10.1016/j.resconrec.2012.09.006

Shi, L. L., \& Ye, J. (2013). Study on fault diagnosis of turbine using an improved cosine similarity measure for vague sets. Journal of Applied Sciences, 13(10), 1781-1786. https://doi.org/10.3923/jas.2013.1781.1786

Shidpour, H., Bernard, A., \& Shahrokhi, M. (2013). A group decision-making method based on intuitionistic fuzzy set in the three dimensional concurrent engineering environment: A multi-objective programming approach. Procedia CIRP, 7, 533-538. https://doi.org/10.1016/j.procir.2013.06.028

Phong, P. H., \& Son, L. H. (2017). Linguistic vector similarity measures and applications to linguistic information classification. International Journal of Intelligent System, 32, 67-81. https://doi.org/10.1002/int.21830

Szmidt, E., \& Kacprzyk, J. (1996). Intuitionistic fuzzy sets in group decision making. Notes on IFS, 2(1), 11-14.

Szmidt, E., \& Kacprzyk, J. (2004). A similarity measure for intuitionistic fuzzy sets and its application in supporting medical diagnostic reasoning. In International Conference on Artificial Intelligence and Soft Computing (ICAISC 2004) (pp. 388-393). Berlin, Heidelberg: Springer. https://doi.org/10.1007/978-3-540-24844-6_56

$\mathrm{Xu}, \mathrm{Z}$. S. (2006). On correlation measures of intuitionistic fuzzy sets. Lecture Notes in Computer Science, 4224, 16-24. https://doi.org/10.1007/11875581_2

Xu, Z. S. (2007a). Method for aggregation interval-valued intuitionistic fuzzy information and their application to decision making. Control and Decision, 22(2), 215-219.

$\mathrm{Xu}, \mathrm{Z}$. S. (2007b). Some similarity measures of intuitionistic fuzzy sets and their applications to multiple attribute decision making. Fuzzy Optimization and Decision Making, 6(2), 109-121. https://doi.org/10.1007/s10700-007-9004-z

$\mathrm{Xu}, \mathrm{Z}$. S. (2010). Choquet integrals of weighted intuitionistic fuzzy information. Information Sciences, 180(5), 726-736. https://doi.org/10.1016/j.ins.2009.11.011

$\mathrm{Xu}, \mathrm{Z}$. S., \& Hu, H. (2010). Projection models for intuitionistic fuzzy multiple attribute decision-making. International Journal of Information Technology \& Decision-Making, 9(2), 267-280. https://doi.org/10.1142/S0219622010003816 
Ye, J. (2011). Cosine similarity measures for intuitionistic fuzzy sets and their applications. Mathematical and Computer Modelling, 53, 91-97. https://doi.org/10.1016/j.mcm.2010.07.022

Ye, J. (2016). Similarity measures of intuitionistic fuzzy sets based on cosine function for the decision making of mechanical design schemes. Journal of Intelligent \& Fuzzy Systems, 30(1), 151-158. https://doi.org/10.3233/IFS-151741

Zhou, B. (2016). A new similarity measure of intuitionistic fuzzy sets considering abstention group influence and its applications. Journal of Intelligent Systems, 25(2), 197-208.

Zhou, B., Zhao, R., Yu, F., \& Tian, H. (2016). Intuitionistic fuzzy entropy clustering algorithm for infrared image segmentation. Journal of Intelligent \& Fuzzy Systems, 30(3), 1831-1840. https://doi.org/10.3233/IFS-151894

Zadeh, L. A. (1971). Similarity relations and fuzzy orderings. Information Sciences, 3(2), 177-200. https://doi.org/10.1016/S0020-0255(71)80005-1

Zeng, W., \& Wang, J. (2011). Correlation coefficient of interval-valued intuitionistic fuzzy sets.In International Conference on Fuzzy Systems and Knowledge Discovery (FSKD) (pp. 98-102). IEEE. https://doi.org/10.1109/FSKD.2011.6019507

Wei, C. P., Wang, P., \& Zhang, Y. Z. (2011). Entropy, similarity measure of interval-valued intuitionistic fuzzy sets and their applications. Information Sciences, 181, 4273-4286. https://doi.org/10.1016/j.ins.2011.06.001

Winter, F. W. (1979). A cost-benefit approach to market segmentation. Journal of Marketing, 43, 103-111. 